\title{
LEITURA E INFÂNCIA: A PRODUÇÃO DOS MODOS DE SER E PRÁTICAS DE LEITURA
}

\author{
Karen Cristina Cavagnoli ${ }^{\mathrm{A}}$ \\ Betina Hillesheim ${ }^{2}$ \\ Lílian Rodrigues da Cruz ${ }^{3}$
}

\section{RESUMO}

Este trabalho propõe discutir a produção da infância em relação à prática da leitura. Para isso, a partir dos sentidos produzidos sobre a leitura na perspectiva das crianças leitoras, considera-se tais práticas como território de produção de sujeitos. Entende-se que a prática da leitura produz modos de existência, os quais não se referem somente às crianças, mas também às maneiras pelas quais os adultos as compreendem e se relacionam com elas e consigo. A produção de dados ocorreu a partir da realização de grupos focais formados por crianças de $4^{a}$ série do ensino fundamental. Os resultados apontam para sentidos distintos, mas que se entrecruzam: leitura associada ao prazer e à obrigação; leitura pressupondo tempos e espaços. Tais marcadores evidenciam a produção de um leitor no âmbito das práticas de leitura que passa preferencialmente pelo discurso pedagógico.

Palavras-chave: Infância. Leitura. Modos de Subjetivação

\section{INTRODUÇÃO}

A prática da leitura pode ser entendida como um território onde se constroem sujeitos e que assume diversas características em cada momento histórico. Desse modo, este estudo investiga quais as relações entre a prática da leitura e a infância, uma vez que as composições possíveis entre leitura e infância

1 Acadêmica do Curso de Psicologia da Universidade de Santa Cruz do Sul -(UNISC). Bolsista do Programa de Iniciação Científica do CNPq - PIBIC. E-mail: karenzotti@yahoo.com.br

2 Doutora em Psicologia (PUCRS), docente do departamento de Psicologia e do Mestrado em Educação da Universidade de Santa Cruz do Sul (UNISC). - betinahillesheim@gmail.com

3 Doutora em Psicologia (PUCRS). Docente e pesquisadora do departamento de Psicologia da Universidade de Santa Cruz do Sul (UNISC). Bolsista de Pós-Doutorado Júnior do CNPq. liliancruz2@terra.com.br 
resultam nas mais variadas formas de compreender e de se relacionar com as crianças.

A noção da infância como construção social implica refutar quaisquer ideias essencialistas sobre a mesma, desnaturalizando esse conceito e abrindo a possibilidade de se pensar sobre as condições históricas, políticas, econômicas e sociais que tornaram possível pensar o que venha a ser infância.

Áries (1981) discute como a noção moderna de infância consolidou-se a partir do século XVII; entretanto, tal concepção é, muitas vezes, entendida como atemporal, pressupondo a existência de uma natureza infantil. Apesar de esse autor utilizar a expressão 'descoberta da infância', Ghiraldelli (2000) considera que os seus estudos não apontam para uma noção da infância como uma etapa natural da vida dos seres humanos que sempre existiu e somente necessitava ser reconhecida como tal, mas como uma 'invenção', ou seja, algo que é montado a partir de novas formas de ver e dizer sobre a infância.

Os estudos de Ariès (1981) identificam esta construção da infância a partir de dois sentimentos: a paparicação (visto que as crianças encantavam e distraíam os adultos) e a preocupação com a racionalidade dos costumes e com a disciplina (que se originou, de certo modo, como reação aos efeitos da paparicação e que proveio de fontes externas à família, tais como eclesiásticos e juristas, que entendiam as crianças como seres frágeis que necessitavam de proteção, orientação moral e disciplinamento). Além disso, destaca a importância da escola no processo de construção da infância moderna. No século XIII as escolas não tinham o objetivo de ensino, mas se constituíam em asilos para estudantes pobres. É a partir do século XV que as escolas tornaram-se instituições não apenas de ensino direcionadas a populações numerosas, mas também de vigilância e esquadrinhamento das condutas infantis.

No que se refere à literatura infantil, essa surge a partir de uma série de modificações que ocorrem a partir do século XVIII, filiando-se à instituição escolar em seu propósito de construção de uma sociedade burguesa. Dessa maneira, a literatura infantil, desde seu início, é vinculada à pedagogia (ZILBERMAN; MAGALHÃES, 1987). Como salienta Zilberman (2001), a primeira e mais duradoura teoria da leitura priorizou o papel do ensino e da pedagogia, partindo da alfabetização como forma de chegar ao texto literário, 'lócus' privilegiado da leitura e destinado à elite intelectual. É a partir da necessidade, gerada pelo capitalismo, de qualificar a mão de obra e também de constituir um mercado consumidor, que a teoria da leitura não pôde mais ser atrelada somente à literatura. O letramento tornou-se, assim, um segmento independente das teorias da leitura na área da educação.

Com a Modernidade, é implantada a escolarização abrangente, ocupando-se a escola, em conjunto com outras instituições, da governamentalidade ${ }^{4}$ da

4 O conceito de governamentalidade foi desenvolvido por Foucault (2006) e é entendido como um conjunto de práticas de governamento que têm na população seu objeto e que busca

Revista Jovem Pesquisador, Santa Cruz do Sul, v. 1, p. 82-88, 2010. 
população, especialmente a infantil, e de seu disciplinamento. A escola, através do discurso pedagógico, produz a infância, tornando-a uma infância-escolar, a qual é examinada, enquadrada e normalizada (CORAZZA, 2000).

Este trabalho investigou quais os sentidos produzidos sobre a leitura na perspectiva das crianças e quais as implicações da prática da leitura na construção da infância. Para tanto, como procedimentos metodológicos, foram realizados seis grupos focais ${ }^{5}$, formados por 6 a 8 crianças, de ambos os sexos, da $4^{a}$ série do ensino fundamental, estudantes de uma escola particular e de duas escolas públicas, em uma cidade brasileira de médio porte. A seguir, discute-se os resultados desta pesquisa, os quais apontam para sentidos distintos, mas que se entrecruzam: leitura associada ao prazer e à obrigação; leitura pressupondo tempos e espaços.

\section{COMPONDO SENTIDOS SOBRE A LEITURA}

A partir da produção de dados, percebe-se que, para as crianças, o ato de ler é marcado por dicotomias: prazer $\mathrm{x}$ obrigação, liberdade $\mathrm{x}$ aprisionamento. Para as crianças, ler é tanto sinal de inteligência ${ }^{6}$, possibilidade de aprendizagem dos conteúdos escolares, exercício para o cérebro e forma de atender às exigências adultas, como fuga, viagem para outro mundo, diversão e prazer.

Estas falas infantis remetem ao lugar atribuído socialmente à leitura, ou seja, que esta se constitui como imprescindível para a formação infantil, na medida em que se compreende a infância como uma fase de preparação para a vida adulta. Embora a leitura adquira para as crianças um caráter ligado ao prazer, também está fortemente vinculada ao pedagógico, ou seja, a leitura aparece como veículo para o saber e, especialmente, para o mundo adulto, sendo que ler é algo valorizado pelo que pode ensinar.

Ressalta-se, seguindo Narodowsky (2001), os seguintes enunciados que conformam a pedagogia moderna, os quais são complementares: a infância caracteriza-se tanto como um conjunto de carências como um campo de análise, necessitando da educação para superar sua condição de inferioridade. Desse modo, "a pedagogia pedagogiza a infância na medida em que já não vai ser

extrair dela seu saber, encontrando nos dispositivos de segurança seus mecanismos básicos (MACHADO, 1992).

5 Grupos focais são uma ferramenta de entrevista em grupo, na qual, a partir de um tema gerador, há a possibilidade de interação e argumentação entre os participantes. Para ser eficaz, o número de participantes não deve ser excessivo e a temática deve ser delimitada, sendo que o pesquisador apresenta algumas questões abertas, propiciando a expressão dos participantes (LAVILLE; DIONNE 1999). Ceres Víctora, Daniela Knauth e Maria de Nazareth Hassen (2000) colocam que se trata de uma técnica qualitativa na qual tópicos ou focos são explorados com o auxílio de um facilitador, podendo ser utilizado sozinha ou com outras técnicas associadas.

6 No decorrer do texto, as falas das crianças, quando literais, encontram-se em itálico. 
possível pensar a infância sem recorrer a categorias e conceitos pedagógicos" ( $\mathrm{p}$. 187).

Ao invés de compreender prazer e obrigação como opostos, podemos colocá-los como faces de uma mesma produção discursiva: na medida em que se encontra prazer na leitura (e aqui se aponta todo o mercado livreiro voltado para o público infantil, assim como as prescrições direcionadas a pais e professores no sentido de incentivar as crianças, desde muito pequenas, à leitura), atinge-se mais plenamente o objetivo final. Goulart (2000), em uma pesquisa sobre os catálogos de livros infantis, pontua os discursos que colocam a leitura a partir de um imperativo do prazer no intuito de governar a infância, isto é, agindo no disciplinamento e controle dos corpos infantis. $O$ uso do termo governo é aqui empregado em uma perspectiva foucaultiana, para a qual esta é uma questão que emerge no século XVI, aliando-se ao poder disciplinar e referindo-se a problemas muito diversos, tais como o governo de si, o governo das almas, das condutas, das crianças, das mulheres, dos doentes, etc. O governo implica, assim, dispor das coisas, com o propósito de alcançar determinadas finalidades, utilizando-se mais de táticas do que de leis (FOUCAULT, 2003).

Outro aspecto a ser salientado é que, usualmente, a leitura cola-se à literatura; contudo, apesar do lugar de destaque dado ao livro, as crianças associam 0 ato de ler a variados artefatos: jornal, revista, camiseta, placa de trânsito, etiqueta de roupa, contrato, manual de instruções, etc. Porém, o texto literário como fim a ser alcançado ocasiona a desvalorização da leitura de outros artefatos culturais, o que é lembrado, de forma bem-humorada, na epígrafe do livro 'Leituras à revelia da escola': "- Vão guardando estas revistinhas aí, que a aula agora é de leitura, interpretação de texto!" (MAFRA, 2003).

Assim como há a desvalorização desses outros artefatos (como é o caso dos gibis, citados acima), percebe-se uma hierarquização no que se refere ao próprio objeto livro. Da mesma forma como a adjetivação infantil confere à literatura uma diminuição do valor artístico da obra, a qual é entendida como uma literatura 'menor' (LAJOLO e ZILBERMAN, 1999), as crianças consideram que um livro pequeninho, repleto de imagens, é mais infantil que aqueles que são mais volumosos e com bastante texto. As falas das crianças vêm marcar nitidamente quais os tipos de leitura direcionados às mesmas, explicitando-se, assim, uma desvalorização do que é infantil, compreendido como de leitura facilitada. Portanto, as crianças avaliam a si próprias e a leitura em relação aos adultos; ler livros com muito texto aproxima-as do universo adulto, fazendo-as sentirem-se mais capazes.

Nessa perspectiva, Mortatti (2000) coloca que o qualificativo infantil vinculase a um leitor previsto, marcando determinadas concepções de infância, as quais tomam como parâmetro o adulto, sendo a criança considerada como um ser 'em desenvolvimento' que necessita da escolarização para assumir seu lugar na sociedade. 


\section{MODOS DE LER E A CONSTRUÇÃO DA CRIANÇA LEITORA}

Historiadores das práticas de leitura, tais como Chartier (1999), apontam que é recente a ideia da leitura como um ato privado, realizado de forma individual e na intimidade. Nos meios urbanos, entre os séculos XVII e XVIII, existia todo outro conjunto de relações com os textos que passava pelas leituras coletivas, decifrados uns pelos outros e muitas vezes com uma elaboração partilhada por todos.

Além disso, como lembra Goulemot (1996), a leitura supõe determinadas posições do corpo: o corpo leitor cansa ou fica sonolento, boceja, experimenta várias dores, encontra-se sentado, deitado ou estirado, etc. Há ainda uma história de representações sobre a leitura, que inclui, por exemplo, fotos ou pinturas que retratam o leitor, que carregam consigo modelos do ato de ler. Livro e corpo entrelaçam-se, sendo a escola um espaço significativo no disciplinamento do corpo, impondo atitudes consideradas adequadas ao leitor (como, por exemplo, cabeça entre as mãos sugerindo uma leitura profunda).

No presente estudo, as crianças referiram que as primeiras experiências de leitura ocorreram em uma situação de convívio familiar, inserindo-se em uma rotina de contar histórias na hora de dormir, através da intermediação dos adultos, especialmente dos pais. A alfabetização marca a passagem da leitura para uma prática individualizada, que não depende mais da mediação adulta. Além disto, os modos de ler relacionados pelas crianças assinalam, mais uma vez, tanto os aspectos pedagógicos como prazerosos na relação com a leitura, os quais são determinados por questões relativas ao tempo e espaço.

A obrigatoriedade dessa atividade na escola define determinados tempos e espaços considerados apropriados à leitura, assim como posições assumidas pelos leitores. As crianças discorrem sobre as denominadas 'horas de leitura', as quais se caracterizam por uma leitura silenciosa, pela escolha de livros 'apropriados', por um tempo previamente definido e por uma posição considerada adequada. Por outro lado, elas identificam tempos e espaços nos quais há a possibilidade de outra relação com a leitura, além das questões pedagógicas: pode-se ler na cama, estirado no chão, na posição de 'indiozinho', quando não há nada para fazer ou, simplesmente, quando dá vontade.

Nessa perspectiva, Paulino et al. (2001) assinalam que olhos, mãos, pescoço, ombros - enfim, todo o corpo do leitor - estão comprometidos no ato de leitura, buscando a sociedade, incessantemente, impor formas de controle desse corpo, ditando espaços e posições específicos, os quais se relacionam com a busca de controle da própria produção de sentidos.

Por sua vez, Morais (2002) critica o modo como a escola comumente entende a leitura, desconsiderando as diferentes leituras do mundo e postulando uma série de situações pedagógicas que se voltam para o corpo, a concentração, os movimentos dos olhos e dos lábios, etc. A leitura torna-se uma forma de 
regulação do tempo individual, inserindo-se em um processo de docilização dos corpos.

Para finalizar, assinala-se que é característico que, em cada tempo e sociedade, circulem discursos que carregam determinadas aspirações sobre a infância. Considerando-se tais questões, entende-se que a valorização da leitura inscreve-se no âmbito da arte de governar a infância, visando à conformação de corpos dóceis e úteis à sociedade. $\mathrm{O}$ ato de ler implica determinadas regulações, as quais passam, predominantemente, pelo espaço escolar, cimentando as relações entre criança e escola. Desse modo, a leitura articula, ao mesmo tempo, prazer e obrigação, tornando-os indissociáveis (é preciso gostar de ler!), o que exerce sobre outros discursos uma espécie de pressão e um poder de coerção, estabelecendo um saber sobre a infância que investe na criança e normatiza condutas.

\section{REFERÊNCIAS}

ARIÈS, Philippe. História social da criança e da familia. 2 ed. Rio de Janeiro: Zahar Editores, 1981.

CHARTIER, Roger. $A$ aventura do livro: do leitor ao navegador. São Paulo: UNESP, 1999.

CORAZZA, Sandra Mara. História da infância sem fim. Ijuí: Unijuí, 2000.

FOUCAULT, Michel. Ditos e escritos IV. Estratégia, poder-saber. Rio de Janeiro: Forense Universitária, 2003.

GHIRALDELLI, Paulo Jr. As concepções de infância e as teorias educacionais modernas e contemporâneas. Educação e Realidade, v.4, n. 1, p. 45-58, dezjan/jul. 2000.

GOULART, Maria Alice H. O prazer como imperativo, a literatura como meio, os corpos dóceis como fim. O micropoder dos catálogos de livros infantis. Dissertação (Mestrado) Universidade Federal do Rio Grande do Sul, Porto Alegre, 2000.

GOULEMOT, J. M. Da leitura como produção de sentidos. In: CHARTIER, Roger (Org.). Práticas da leitura. São Paulo: Estação Liberdade, 1996. p. 107-116.

LAJOLO, Marisa; ZILBERMAN, Regina. Literatura infantil brasileira: história \& histórias. 6 ed. São Paulo: Ática, 1999.

LAVILLE, Christian; DIONNE, Jean. Em busca de informações. In - A construção do saber: manual de metodologia da

pesquisa em ciências humanas. Porto Alegre: Artemed; Belo Horizonte: UFMG, 1999. p. $165-195$.

MACHADO, R. Introdução: por uma genealogia do poder. In: FOUCAULT, M. Microfísica do poder. 10. ed. Rio de Janeiro: Graal, 1992. p. vII-XXIII.

MAFRA, Nubia Delame F. Leituras à revelia da escola. Londrina: Eduel. 2003. 
MORAIS, J. de F. S. Histórias e narrativas na educação infantil. In: GARCIA, R. L. (Org.). Crianças, essas conhecidas tão desconhecidas. Rio de Janeiro: DP\&A, 2002. p. $81-102$.

PAULINO, G.; WALTY, I.; FONSECA, M.N.; CURY, M.Z. Tipos de texto, modos de leitura. Belo Horizonte: Formato, 2001.

MORTATTI, Mara do Rosário L. Leitura crítica da literatura infantil. Leitura: Teoria e Prática, 2000, p.11-16, ano 19, n. 36.

NARODOWSKI, Mariano. Infância e poder: conformação da pedagogia moderna. Bragança Paulista: Editora da Universidade São Francisco, 2001.

VÍCTORA, C.G.; KNAUTH, D.R.; HASSEN, M.N.A. Pesquisa qualitativa em saúde: uma introdução ao tema. Porto Alegre: Tomo editoral, 2000.

ZILBERMAN, Regina; MAGALHÃES, Lígia C. Literatura infantil: autoritarismo e emancipação. 3 ed. São Paulo: Ática, 1987.

ZILBERMAN, Regina. Fim do livro, fim dos leitores?São Paulo: SENAC, 2001. 